\title{
The Effects of Teaching Mathematics Performed with the Help of CSCM on Conceptual Learning
}

\author{
Ramazan Gürbüz ${ }^{1}$, Emrullah Erdem ${ }^{1}$, Selçuk Frrat ${ }^{2}$ \\ ${ }^{1}$ Department of Elementary Mathematics Education, Faculty of Education, Adiyaman University, \\ Adiyaman, Turkey \\ ${ }^{2}$ Department of Computer Education and Instructional Technology, Faculty of Education, Adiyaman University, \\ Adiyaman, Turkey \\ Email: rgurbuz@outlook.com, eerdem@outlook.com,sfirat02@gmail.com
}

Received September $3^{\text {rd }}, 2012$; revised October $5^{\text {th }}, 2012$; accepted October $19^{\text {th }}, 2012$

\begin{abstract}
This paper explores the effect of teaching mathematics performed with the help of Computer-Supported Concept Maps (CSCM) on the conceptual learning. To achieve this end, CSCM were developed and used in the process of teaching probability subject. Within the true-experimental research method, a pre- and post-test control groups study was conducted with 39 seventh graders-20 in experimental group, and 19 in the control group. Each group was taught three times/week, $40 \mathrm{~min} / \mathrm{session}$, for 2 weeks. A 12 -item instrument was used to collect data. After the teaching intervention, the same instrument was re-administered to both groups as post-test. The results suggested that students in the experimental group performed significantly better than those in the control group, in terms of conceptual learning.
\end{abstract}

Keywords: Teaching Mathematics; Computer-Supported Concept Maps (CSCM); Conceptual Learning; Cooperative Learning; Probability

\section{Introduction}

The main purpose of education is to teach students the nature of knowledge based on concepts. Concepts can be defined as generalised and symbolised aspect of an encountered event or a learned object. In showing concepts and relationships between them, Concept Maps (CM) are among very important materials. CM strategy, which shows how people learn and make sense of knowledge, was developed as a result of the research project carried out with students studying in University of Cornell by Joseph Novak in the year 1974. CM are defined as tools revealing the connections between the concepts in the form of hierarchical and cross-linking (Willerman \& Harg, 1991). CM strategy is an educational strategy aiding students in comprehending subjects, in integrating old and new knowledge, in improving their perceptional levels, and in increasing their success (Heinze-Fry \& Novak, 1990). In this sense, it is thought that CM strategy which has been frequently used recently (Anderson-Inman \& Zeitz, 1993; Jonassen, 1996; AndersonInman, Ditson, \& Ditson, 1998; Novak \& Cañas, 2006) can be an effective teaching strategy. But it is more difficult to determine all the probable relationships in a large content concept map and to put them on a limited space on a paper (Novak \& Gowin, 1984; Gürbüz, 2006a). For this reason, in recent years, Computer-Supported Concept Maps (CSCM) that have unlimited space are employed as teaching materials in learning environments.

\section{Computer-Supported Concept Maps (CSCM)}

CSCM, which are one of the most effective tools in concreteization of abstract concepts, are important teaching materials (Anderson-Inman \& Ditson, 1999), because in the CSCM; concepts, connections, and formulas which have been placed into the gaps in the map are shown on a virtual platform. In this way, students have the opportunity to select among these concepts, connections, and formulas (Chang, Sung, \& Chen, 2001; Tsai, Lin, \& Yuan, 2001). The importance of CSCM is also because they give the opportunity to construct knowledge visually (Gürbüz, 2006a), to construct their concept maps via feedbacks given in computer environment (Chang et al., 2001) and to make learners engaged (Novak \& Gowin, 1984; AndersonInman \& Zeitz, 1993). In addition to these, CSCM provide a lot of advantages such as being able to save and to print documents, to make changes if required, to create big maps, to make connections and to zoom (Rautama, 2000). Moreover, practicality, dynamic linking, digital communication, and digital recording can be considered to be the other advantages of the CSCM.

The literature mentioned the positive effects of combining computer software with concept maps in learning environments (Anderson-Inman \& Zeitz, 1993; Anderson-Inman \& Horney, 1996; Anderson-Inman \& Ditson, 1999; Simone, Schmid, \& McEwen, 2001; Chang, Sung, \& Chen, 2002; Baki \& Mandac1Şahin, 2004; Kwon \& Cifuentes, 2009; Chiu \& Hsiao, 2010; Huang et al., 2012). For example, Anderson-Inman \& Horney (1996) indicated that computer-based visualization made learning process more accessible to students, and it alleviates the frustration felt by students during the process of constructing and revising concept maps using paper and pencil. AndersonInman \& Ditson (1999) stated that CSCM ensured the concreteization of abstract concepts and thus they could be used in learning environments effectively. In another study, Kwon and Cifuentes (2009) pointed out that the computer-based concept mapping was facilitative of knowledge construction.

The cooperative goal structure is also an important factor in order for enhancing the effectiveness of CSCM strategy. This is because the cooperative learning environment requires students 
to work in small, mixed-ability learning groups (Slavin, 1987). The cooperative learning approach increases students' motivation to learn mathematics while it also enables them to have fun doing that (Johnson \& Johnson, 1989) and it helps the students focus on the subject or task by enabling them to work with each other and by providing a comfortable environment to work in (Slavin, 1996). In conjunction with increasing use of computer technology, this cooperative learning approach can be performed in computer-supported learning environments more effectively. According to Ledesma (2010), computer technology makes it possible for the students using it to develop skills that are not developed by other students using pencil and paper and blackboard. In this sense, Matin (2012) points out that computer-supported learning environments will engage students, give positive interdependence, face-to-face interaction, and will help them develop interpersonal skills and individual accountability in better understanding, critical thinking and judgment. Thus, more effective learning can be ensured by employing the CSCM strategy together with cooperative groups. Recent studies also discussed the positive effects of the instructtions conducted in cooperative groups with the CSCM (Stoyanova \& Kommers, 2002; Brown, 2003; Kwon \& Cifuentes, 2009).

\section{Literature Review Regarding CSCM}

When searching literature, it is possible to encounter with a great deal of studies mentioning positive effects of CSCM. For example, in their study, Anderson-Inman and Zeitz (1993) concluded that computer-based concept mapping using Inspiration TM encouraged students to revise or change their maps more (compared to the maps they drew using paper and pencil) and fostered knowledge representation and construction. In another work, Sturm and Rankin-Erickson (2002) examined the effects of two forms of concept mapping; hand-drawn and computergenerated, on the descriptive essay writing of middle level students with learning disabilities. Results showed that students' hand-written descriptive essays and those produced in computer-mapping conditions demonstrated significant increases. It was also found that students' attitudes towards writing were significantly more positive in computer-mapping condition compared to no-mapping and hand-mapping conditions. Baki and Mandac1-Şahin (2004) carried out a study to determine the pre-service elementary teachers' misconceptions about the subject "set" through CSCM. It was suggested that the students' concept mapping process using the Inspiration ${ }^{\circledR}$ package programme could be used as an effective assessment technique. Royer and Royer (2004) investigated the difference between hand drawn and computer generated concept mapping with 9th and 10th graders. They found that the group using the computers created more complex maps than the others did. Also, they theorised that computers enabled students to communicate more clearly, to add and revise concept maps more easily, and to discover relationships between sub-concepts more readily. Yavuz (2005) examined the effectiveness of conceptual change instruction accompanied with demonstration and computer assisted concept mapping on seventh grade students' understanding matter concepts. The results indicated that this teaching process provided a better acquisition of scientific conceptions related to matter concepts and produced more positive attitudes toward science as a school subject than traditionally designed science instructions. Kwon and Cifuentes (2009) in- vestigated the comparative effects of individually-constructed and collaboratively-constructed computer-based concept mapping on middle school science concept learning. They found that computer-based concept mapping facilitated knowledge construction and the students had a deeper understanding by working collaboratively rather than by working individually. Chiu and Hsiao (2010) studied how elementary school students generated concept maps in computer-supported collaborative learning. They found that almost $70 \%$ of the collaborative groups were classified as passive or reticent and frequently offtask. These student groups were poorly functioning collaborative groups and produced poor quality discourses and products. Also, it was concluded that there was a great need for methods such as training or intervening approaches that could enhance the interaction and improve the quality of the discourse in the computer-mediated collaboration for elementary school students. Huang et al., (2012) explored the effect of multidimensional concept mapping instruction on students' learning performance in a web-based computer course. The 103 fourth graders were divided into three groups: multidimensional concept map (MCM) instruction group, Novak concept map (NCM) instruction group, and traditional textbook (TT) instruction group. The experimental results suggested that subjects in the MCM group performed significantly better than those in the NCM group which in turn performed significantly better than those in the TT group.

As understood from the reviewed literature, CSCM ensure learners perform more effective learnings especially when compared to no-mapping and/or hand-mapping conditions. Therefore, in the current study, we examined the effect of teaching mathematics performed with the help of CSCM on the conceptual learning.

\section{Methodology}

\section{Participants}

Within true-experimental research method, this study was conducted with a total of 39 seventh-grade students from an elementary school in Turkey. These students studying in the same class were divided into two groups according to whether their school numbers were even or odd (experimental group (E) $=20$ and control group $(C)=19)$. Students in experimental group were organized as 2-student cooperative groups (see Figure 1(b)).

\section{Computer-Supported Concept Maps (CSCM) Material}

The CSCM material was developed by NetBeans' editor by using the Java language. While constructing CSCM material, extra attention was paid to ensure that it included all concepts on probability subject taught at 7 th grade level and that relationships between these concepts were given in a concise way. For example, the relationship between "Experiment" and "Result" is stated as "what is gathered from experiment is a result". However, all these concepts and relationships were not given directly; rather, users were given some cues in the system to find them by themselves. For instance, some cues such as "it takes values ranging from 0 to 1 " and "it is a concept related to chance" were given for the space in which "probability" concept was to be placed. If the user puts a wrong concept, link or 


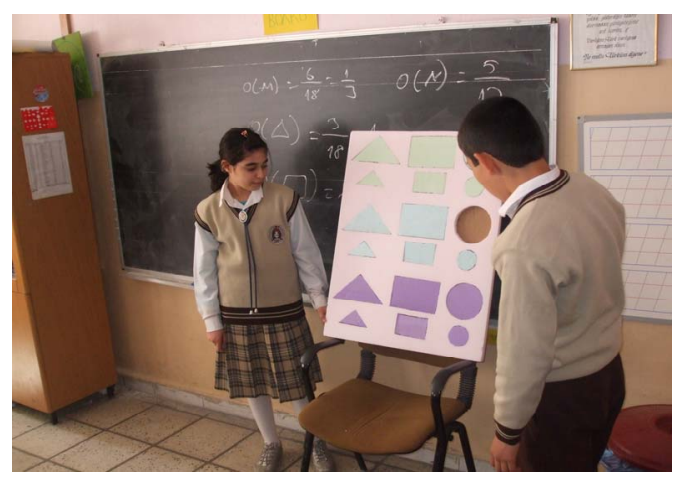

(a)

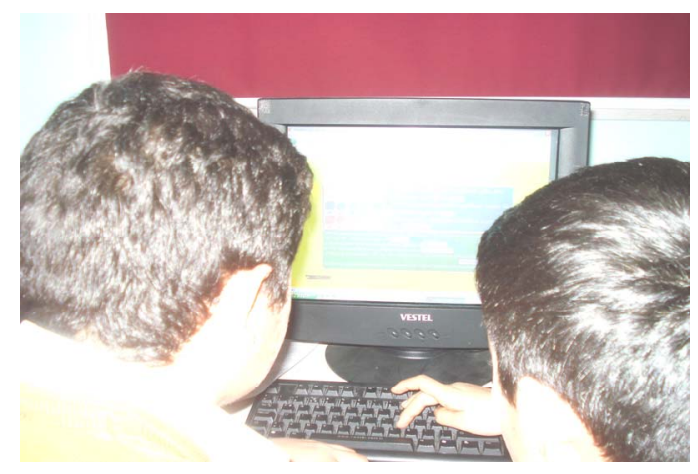

(b)

Figure 1.

Reflections from experimental group.

formula into the system, "you have entered wrong info" feedback is shown on the screen and, thus, the first cue that will lead the user to correct answer is provided. If the user enters wrong info despite this cue, system gives another cue with a more explanatory feedback. For example, when the user writes "Not-Mutually Exclusive Event" upon seeing the cue "the probability of a randomly selected geometric shape from the screen to be red or hexagon, is related to ... concept", system gives the feedback "Congratulations! Correct Answer". If the user writes "Mutually Exclusive Event" upon seeing the same cue, system presents another cue (Cue 2) such as "do these two incidents have common units or not?" When, however, the user who cannot find the correct answer despite all these cues, clicks on the Cue 2 in Figure 2, the system will give another more detailed explanation to the user such as: "Let us calculate the probability of a geometric shape selected randomly from the screen in Figure 2 to be red or square together. After analyzing the screen, it is possible to see that when the geometric shape is both red and square, we call this 'Not-Mutually Exclusive Event'. Therefore, the probability of these two incidents can be calculated by this formula: $P(R U S)=P(R)+P(S)-P(R \cap S)$. The reason why we subtract $P(R \cap S)$ is that we use red squares both when calculating red shapes and squares". This material improves students' self-confidence both because it motivates them and also because it helps create a learning environment in which they can construct information by themselves. Moreover, since this material creates an environment in which students discover the relationships between concepts by themselves, it gives users opportunity to build new relationships they do not anticipate.

This material was pilot-studied with 18 seventh-grade stu- dents who did not participate in the real study and were divided into nine groups each consisting of two students. By using the pilot study, the probable deficiencies of the material and the problems, which could be encountered during the application process, were determined and necessary corrections were made.

A sample interface from the designed material is illustrated in Figure 3.

\section{Instrument}

The instrument used (Conceptual Learning Test-CLT) was composed of 12 questions (some of them were given in Appendix) which were in open-ended format. Some of the questions were developed by the researchers, and some were developed with the help of related literature (Fast, 1997; Pratt, 2000; Baker \& Chick, 2007; Nilsson, 2007, 2009; Gürbüz, 2006b; 2010).

The validity of the instrument was confirmed by two mathematics educators and two mathematics teachers. Furthermore, the pilot test was performed with 34 seventh-grade students who did not participate in the real study. The pilot study revealed that questions on the subject of probability were understandable and clear for seventh-grade students. In this study, the Kuder-Richardson formula 20 (KR-20) reliability coefficient of the instrument was found to be 0.88 .

\section{Procedure}

The CLT was administered to both groups as a pretest before instructions. Both groups were encouraged to answer all the questions. A researcher managed the experimental group, while the maths teacher in the study managed the control group by conducting the application process simultaneously. The remaining two researchers participated in the study as observers for experimental and control groups by rotating. Each group was taught three times/week, $40 \mathrm{~min} / \mathrm{session}$, for 4 weeks. After the instructions, CLT was re-administered to both groups as a posttest.

In experimental group, some questions related to daily life such as "what does scoring a goal through a penalty shoot de-

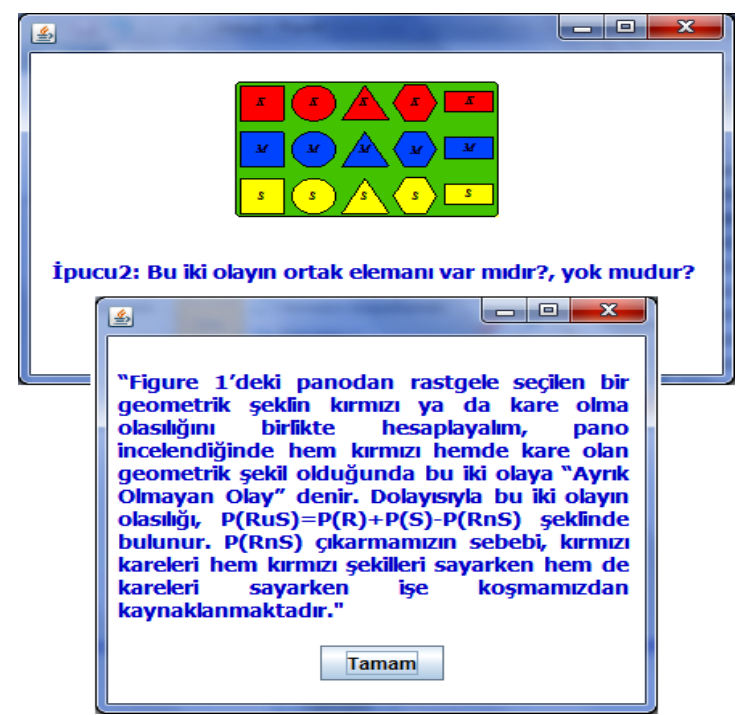

Figure 2.

A sample cue and explanation given to users by the system. 


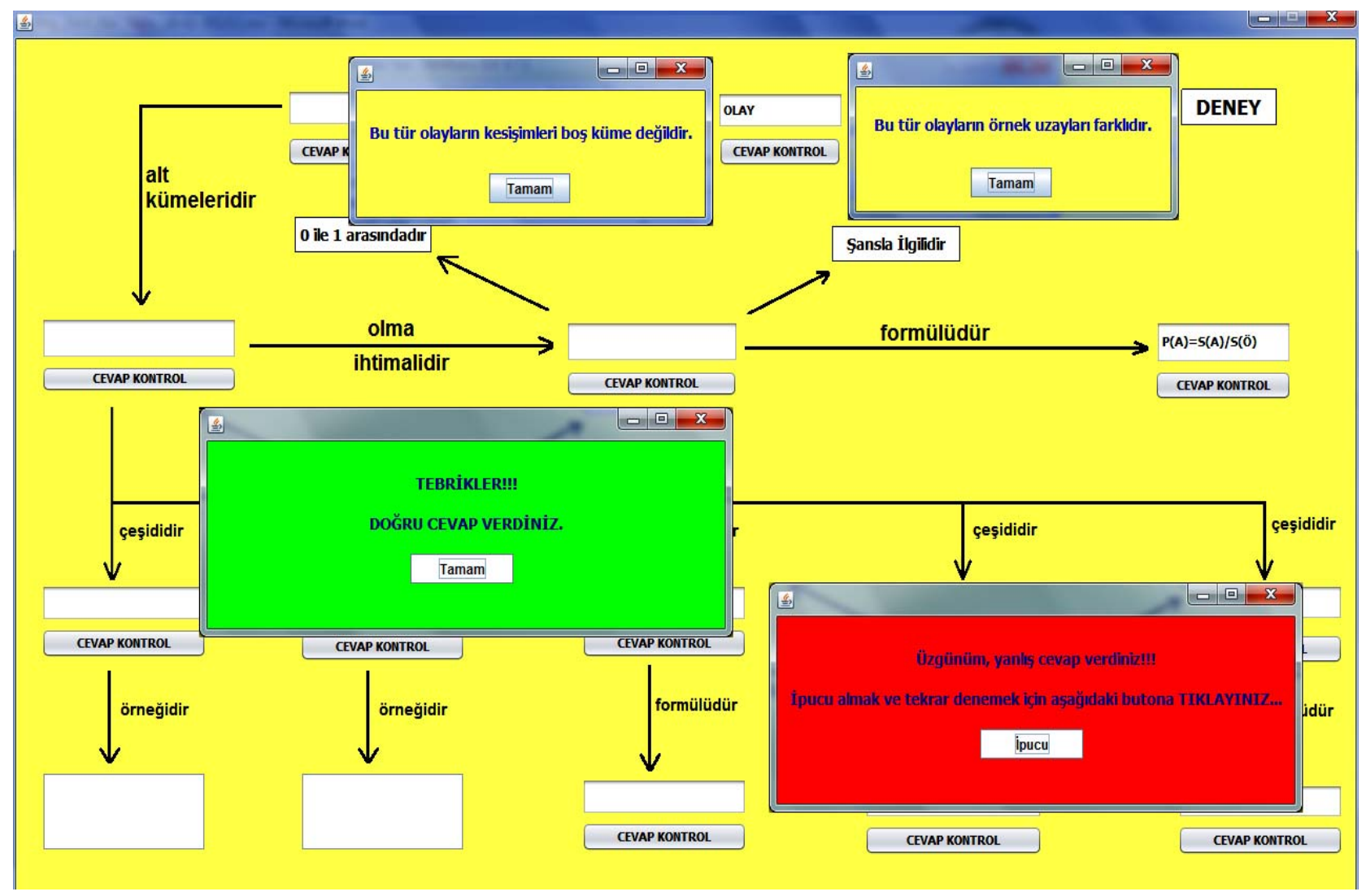

Figure 3.

An interface from CSCM material

pend on?", "the probability of having rain in Adiyaman is $1 / 4$. How do you think I got it?" were asked to students. After these questions had been discussed with students for a while, teaching of probability concepts were performed with materials (spinners, dice, dart, board etc. (see Figure 1(a)) by an experienced researcher. Then, CSCM was employed in teaching process after students had been informed about CM and CSCM. In this process, the students were requested to run the computer animations, and they were asked to share their thoughts with their partners. Moreover, the student groups asked questions to each other such as "why are you doing that?" and "how did you get that?" or made statements such as "oh no, that is not right, because..." and "...but that is wrong, because..." during the implementations. This process was ensured by devoting considerable class time to solving problems, proposing and justifying alternative solutions, critically evaluating alternative courses of action, leading to different methods of solving problems. Students are expected and encouraged to make conjectures, explain their reasoning, validate their assertions, discuss and question their own thinking and the thinking of others, and argue what is mathematically true. Also during this process, the researcher acted as a counselor, cooperator, and supervisor. As a result, students became more active, improved their knowledge, questioned the knowledge they received, and were able to explain what they had just learned instead of behaving as merely passive receivers. In other words, it could be stated that students in this group learnt subjects the way they wanted. For instance, they reached solution of any given question by conducting limitless experiments, by using tree diagrams and by discussing among themselves as they wished.

In the control group, the instructions were performed on a teacher-centered basis and delivered verbally, according to the book. The teacher (usual teacher) would note down the necessary points on the chalkboard (talk-and-chalk type instruction). While writing on the board, the teacher framed the important parts using colored chalk. During the process the students sat in their seats silently and listened to the teacher. Then, the teacher gave them some time to take notes from the board. The teacher also asked if they had any questions about the subject. Meanwhile, he walked around the class and answered their questions. In brief, $70 \%-75 \%$ of the probability subject was composed of only the teacher's talk. At the end of the lesson, the teacher asked the students to answer the questions at the end of the unit. In the control group, questions such as "suppose that there are some balls numbered from 1 to 8 in a glass jar. When you close your eyes, mix the balls and choose a ball in the jar, what is the probability of getting a ball numbered with an odd number?" were generated and solved. To sum up, the experiments were done and the results were obtained by imagination without using any other materials or animations. Students in this group learnt based on rules established by the teacher. When a student asked teacher a question while solving a question, the teacher solved it by reminding students of rules he showed before. For example, when a student asked a question such as: "Teacher! Why are we adding the scores? Should not we multiply them instead?" the teacher responded: "Let us remember our rule, if two events are discrete, probability of them are added". 
During the study, most of the students in the control group wondered how their peers in the experimental group were doing. Therefore, they frequently checked the computer laboratory to figure out what was going on there. After hearing from their friends in the experimental group about the applications there, they asked researchers/teachers to add them to this group, as well.

\section{Data Analysis}

The effect of teaching with the help of CSCM and of traditional teaching was investigated by the CLT. Students' answers have been classified according to the levels in a Rubric (see Table 1) developed by Gürbüz $(2007,2010)$. According to the scores presented in Table 1, statistical comparisons of conceptual learning levels of groups were made. To achieve this end, the mean scores gathered from the questions in CLT were calculated. Scores gathered were analyzed through SPSS statistical package program. Data were analyzed using independent samples $t$-test, and analysis of covariance (ANCOVA). In fact, covariance analysis was applied in order to observe any potential difference between the means of the post-test scores of the groups. A Bonferroni pairwise comparisons test was used to determine the direction of differentiation.

\section{Results and Discussion}

Descriptive statistical results of the pretest and posttest for the experimental and control groups are given in Table 2. In this study, the independent samples $t$-test was performed to compare the pretest scores of the groups. The results of the independent samples $t$-test showed that no significant difference was found among the pretest scores of the groups $[t(37)$ $=.487, p=.629]$. Therefore, it can be said that both groups had the same level prior to the instructional process.

In order to compare the effects of the instructional strategies

Table 1.

Criteria used in order to assess CLT.

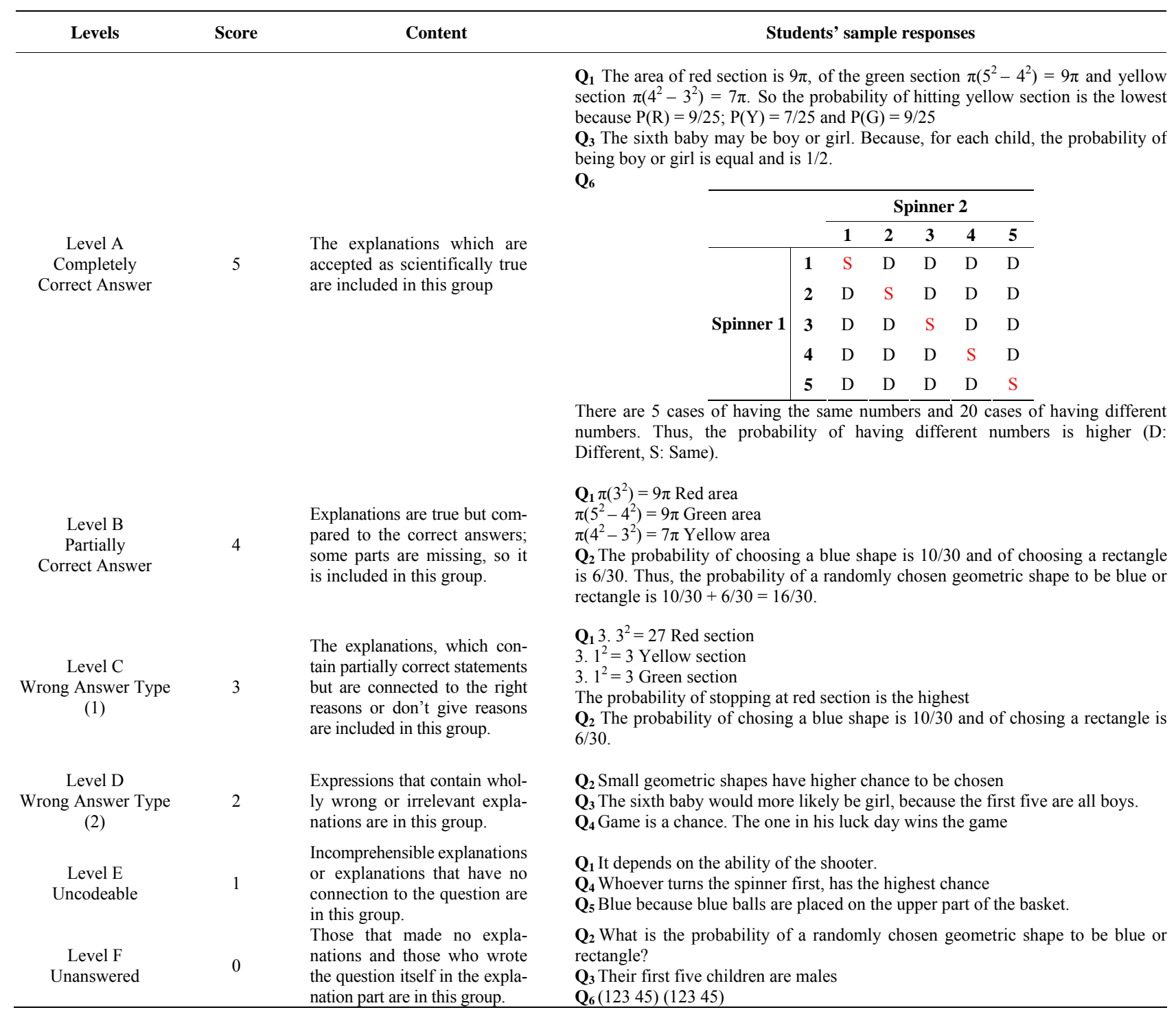

Note: $\mathrm{Q}_{\mathrm{a}}$ : Some question items used in CLT. 
implemented on the groups in the post-test scores using ANCOVA, the tests of homogeneity within the group regression slopes were conducted. As a result of the analysis the slopes were found to be homogenous, as in Group ${ }^{*}$ Pre-test $[F(1-35)$ $=.609, p=.440]$, within the groups. Therefore, a covariance analysis was applied in order to observe any potential difference between the means of the posttest scores of the groups. The result of the one-way ANCOVA is given in Table 3.

As shown in Table 3, the analysis of the posttest score data indicates significant overall intervention effects, controlling the pretest $[F(1,36)=35.946$, Partial $\eta=.500, p<.01]$. Regarding the posttest scores, the students in the experimental group benefitted significantly more than those in the control group (Mean difference $=1.031, p<.01$ ). From the results of the pair-wise test, it can be stated that the CSCM strategy was more effective than the traditional teaching methods in terms of improving conceptual learning. In this study, the effect sizes (partial eta sequared) were calculated to be .500 . It can be stated that the CSCM strategy had a high effect on the conceptual learning according to Cohen (1988). These outcomes corroborate the results of Anderson-Inman \& Zeitz (1993), Anderson-Inman et al., (1998), Simone et al., (2001), Chang et al., (2002), Stoyanova \& Kommers (2002), Brown (2003), Baki \& Mandacı-Şahin (2004), Kwon \& Cifuentes (2009) and Huang et al., (2012).

It could be asserted that researcher teacher factor has also affected this process along with CSCM, because, teacher seldom invited students to present their work to other students and never discussed or allowed students to share unsuccessful attempts. In the contrast, researcher encouraged students to solve problems in any way they desired and to discuss with the whole class their methods as well as their unsuccessful attempts. He also encouraged solution of problems in alternative ways. Clearly, teacher and researcher's students were offered probability theory of different natures. The nature of probability theory made available to learn in teacher's classes was characterized by a domain that deals with final results only, where ways employed to reach these results are not important, and problems are solved by simply following rules developed by experts. In contrast, by participating in the researcher's classes, students were exposed to a different nature of probability theory. The nature of probability theory made available to learn in researcher classes was characterized by a domain that deals

Table 2.

Pretest and posttest scores of the groups.

\begin{tabular}{cccccccc}
\hline \multirow{2}{*}{ Group } & \multirow{2}{*}{$\mathrm{n}$} & \multicolumn{2}{c}{ Pre-test } & \multicolumn{2}{c}{ Post-test } & \multicolumn{3}{c}{ Estimated post-test } \\
\cline { 3 - 8 } & & $\mathrm{M}$ & $\mathrm{SD}$ & $\mathrm{M}$ & $\mathrm{SD}$ & $\mathrm{M}^{*}$ & $\mathrm{SE}$ \\
\hline Experimental & 20 & 1.57 & .66 & 3.12 & .73 & 3.092 & .120 \\
Control & 19 & 1.47 & .59 & 2.02 & .63 & 2.060 & .123 \\
\hline
\end{tabular}

Table 3.

Results of the covariance analysis on post-test scores of the groups.

\begin{tabular}{cccccc}
\hline $\begin{array}{c}\text { Measure } \\
\text { (Post-test) }\end{array}$ & $F$ & $\mathrm{df}$ & $\mathrm{p}$ & Partial $\eta^{2}$ & Direction \\
\hline Overall & 35.946 & $1-36$ & .000 & .500 & \\
$\begin{array}{c}\text { (Bonferroni) } \\
\text { Mean Difference } \\
\text { (I-J) }\end{array}$ & & & & \\
$\begin{array}{c}\text { Experimental (I) } \\
\text { versus Control (J) }\end{array}$ & 1.031 & & .000 & & $\mathrm{I}>\mathrm{J}$ \\
\hline
\end{tabular}

with final results as well as with ways of reaching these results; a domain in which examining mistakes is important and constructive and could help in achieving correct solutions and understanding. In parallel with this, Boaler (1997), Even and Kvatinskt (2010) and Gürbüz, Birgin and Çatlioğlu (2012) also focused on the fact that teachers and different teaching approaches adopted by teachers had a significant influence on students' learning. The researcher referred to the role of probability theory on mathematics and in other domain. Also, he put emphasis on probability theory depending on predictor's knowledge. But, teacher didn't mention any of these cases. What the teacher did not address in class was basically not required explicitly for the examinations and was not included in the textbooks they used, which were closely connected to the examinations. Some related research on teacher anxiety (Black \& Willam, 1998; Ayres, Sawyer, \& Dinham, 2004) also showed that central exams had an effect on learning environments and that these exams encouraged test-based teaching.

It is thought that providing students' pre-test and post-test answers will more clearly show the effect of this intervention. For this reason, explanations related to some questions in CLT made by some of the students of experimental group in the preand post-test were examined carefully.

It was found that the students who had mistakes regarding question $\mathrm{Q}_{1}$ had different justifications for their wrong answers in pretest. For example, "Green because green is on the narrow side of dart", "Red has the highest probability since it is on center", "The probability of targeting on yellow and green colored sections is the lowest because they have smaller radii". As stated by Kahneman (2003), Gürbüz (2007), Gürbüz, Çatlıŏlu, Birgin and Erdem (2010) and Gürbüz and Birgin (2012), these students gave their answers based on their visual intuitions rather than on their logical reasoning. Some of the students were found to give non-mathematical answers such as "It depends on the ability of the shooter" or "It depends on chance, so, no comment can be made". Such approaches of students who gave wrong answers to question $\mathrm{Q}_{1}$ are in line with the student approaches in the studies of Jones, Langrall, Thornton and Mogill (1997), Gürbüz (2007, 2010), Gürbüz et al., (2010), Erdem (2011) and Gürbüz and Birgin (2012). In posttest, when comparing to pretest, the students had more true justifications regarding question $\mathrm{Q}_{1}$. For example, "The area of red section is $9 \pi$, of the green section $\pi\left(5^{2}-4^{2}\right)=9 \pi$ and yellow section $\pi\left(4^{2}-\right.$ $\left.3^{2}\right)=7 \pi$. So the probability of hitting yellow section is the lowest because $P(R)=9 / 25 ; P(Y)=7 / 25$ and $P(G)=9 / 25$ ", "You need to find the area each section covers. $\pi\left(3^{2}\right)=9 \pi$ Red area; $\pi\left(5^{2}-4^{2}\right)=9 \pi$ Green area and $\pi\left(4^{2}-3^{2}\right)=7 \pi$ Yellow area".

It was observed that, in $\mathrm{Q}_{2}$, students' knowledge related to mutually exclusive and not-mutually exclusive events were not sufficient in pretest and thus they gave wrong or incomplete answers for different reasons. For example, responses such as "The probability of getting blue is 10/30 while getting rectangle is 2/30", "The probability of getting blue and rectangle is the same because there is blue color, too, in rectangular shapes" The probability of getting blue and rectangle is $2 / 10$ " were given by the students. On the other hand in posttest, it was found out that students grasped the difference between discrete and indiscrete events. However, it cannot be said that all students understood that there was an intersection set in indiscrete events. For example, " $P(A \mathrm{U} B)=P(A)+P(B)-P(A \cap B)$, the probability of getting blue is $10 / 30$, the probability of getting rectangle is $6 / 30$ and the probability of getting both blue and 
rectangle is $2 / 30$, so, $P(A \mathrm{U} B)=10 / 30+6 / 30-2 / 30=14 / 30$ ", "the probability of getting blue is $10 / 30$, the probability of getting rectangle is $6 / 30 "$, " $P(A \mathrm{U} B)=10 / 30+6 / 30=16 / 30 "$.

It was also found out that the students, who made mistake in Q3 in pretest, also gave different justifications for their wrong answers. For example, The sixth baby would more likely be boy because the first five are all boys", "The sixth baby would more likely be girl because the first five are all boys". Kahneman and Tversky (1972) stated that for a family with 6 children, it's believed that the order of genders will more likely be MFFMFM (M: Male; F: Female) instead of MMMMMM or MMMFFF. It's possible to find similar results in the studies by Fast (1997) and Gürbüz and Birgin (2012). However, it can be suggested that these mistakes disappeared considerably in the posttest. Students gave more correct answers in post-test such as "the probability of a baby being boy or girl is equal and it is 1/2", "The fact that the first five children are boys does not affect whether the sixth baby will be a boy or a girl", "The fact that the first five children are boys does not necessitate the sixth baby to be a boy, so they are equal".

In $\mathrm{Q}_{4}$, students either gave wrong answers or did not give answers at all as they confronted different dice. They gave responses such as "I am not answering that question as this dice is different from the dice we are familiar with", "Ali will win as there are more even numbers", "Veli will win because the probability of total score to be 7 or 9 is higher". Students' such kind of misconceptional answers can be argued to have stemmed from students' lack of sufficient knowledge in sample space concept. Within the same context, Baker and Chick (2007), Bezzina (2004), Chernoff (2009), Fischbein, Nello and Marino (1991), Gürbüz (2007, 2010), Keren (1984), Nilsson (2007), Polaki (2002) and Gürbüz and Birgin (2012) showed in their studies that students' knowledge about sample space concept played an important role in their answers to questions related to probability subject. Some students, on the other hand, gave illogical answers without any mathematical thinking and gave responses such as "Whoever starts earliest will win", "Ali will win because 10 steps they have to take is also an even number", "Whoever is on his/her luck day will win". Polaki (2002) names this type of thinking as subjective probabilistic thinking. However, in posttest, most students corrected the mistakes they made in pretest and gave more logical answers such as "Ali and Veli has equal chance because cases of getting even numbers are $(2,4)$ or $(2,6)$; cases of getting odd numbers are $(3,4)$ or $(3,6)$ ", "we can show this on a table (see Figure $\mathbf{4}(\mathrm{a})$ ). There are equal numbers of even and odd numbers, therefore, the chances of winning are equal for both of them".

Question $\mathrm{Q}_{5}$ is the question that most students answered correctly. Though there were a few wrong answers given, in pretest, students showed overall a good performance in answering it. Explanations related with $\mathrm{Q}_{5}$ given by some of the students in pretest are as follows: "It is green because green ones are on the top of the basket", "since the number of green balls in the basket is higher than others, the probability of getting green is the highest". Here, since the students focused on the location of the balls in question $\mathrm{Q}_{5}$, they made some mistakes. This finding is in line with the findings gathered from studies carried out by Jones et al., (1997), Gürbüz (2007), Gürbüz et al., (2010), Erdem (2011) and Firat (2011). However, it was seen that students gave correct answers to this question in post-test such as "it is green because the number of green balls is the highest", "Since the number of green balls in the basket is higher than others, the probability of getting green is the highest. Numerically, $P(G)=4 / 9$ ".

Question $\mathrm{Q}_{6}$ can be argued to be one of the questions for which the students revealed the highest number of mistakes. For example, there were responses such as "since there are 2 spinners and 5 numbers, probability is 2/5", "because location of numbers are different in 1st and 2nd spinner, the probability of getting different numbers is higher", "the probability of getting different numbers is high because it is generally impossible to get even numbers". These mistakes stem from the fact that students perceive these cases as independent, they lack sufficient knowledge about the concept of sample space. Fischbein et al., (1991), Lecoutre (1992), Batanero and Serrano (1999), Baker and Chick (2007), Nilsson (2007, 2009), Gürbüz (2010), Erdem (2011), Firat (2011) and Gürbüz and Birgin (2012) reported similar conclusions in parallel with this in their studies. It was observed that students gave correct answers to $\mathrm{Q}_{6}$ in posttest. Explanations related with $\mathrm{Q}_{6}$ provided by some of the students in posttest are as follows: "the probability of getting different numbers is higher because there are fewer cases of getting the same numbers $[(1,1)$ or $(2,2),(3,3),(4,4)$, $(5,5)]$ ", "the probability of getting the same numbers is $P(S)=$ $5 / 25$ and the probability of getting different numbers is $P(D)=$ $20 / 25$, so, the probability of getting different numbers is higher (S: Same, D: Different)", "as can be observed on Figure 4(b), there are 5 cases of getting the same numbers and 20 cases of getting different numbers. Thus, the probability of getting different numbers is higher".

These findings can be summarized that the teaching performed with the help of CSCM showed a positive impact on conceptual learning of probability. This positive effect is thought to be provided by CSCM accompanied by a student-centered learning environment. The findings of the present study suggest that different teaching approaches and different teachers are also effective in students' level of learning the subject.

\begin{tabular}{|l|l|l|l|l|l|l|}
\hline+ & 4 & 4 & 4 & 6 & 6 & 6 \\
\hline 2 & 6 & 6 & 6 & 8 & 8 & 8 \\
\hline 2 & 6 & 6 & 6 & 8 & 8 & 8 \\
\hline 2 & 6 & 6 & 6 & 8 & 8 & 8 \\
\hline 3 & 7 & 7 & 7 & 9 & 9 & 9 \\
\hline 3 & 7 & 7 & 7 & 9 & 9 & 9 \\
\hline 3 & 7 & 7 & 7 & 9 & 9 & 9 \\
\hline
\end{tabular}

(a)

\begin{tabular}{ccccccc}
\hline & \multicolumn{6}{c}{ Spinner 2 } \\
\cline { 2 - 7 } & & $\mathbf{1}$ & $\mathbf{2}$ & $\mathbf{3}$ & $\mathbf{4}$ & $\mathbf{5}$ \\
\hline & $\mathbf{2}$ & $\mathrm{S}$ & $\mathrm{D}$ & $\mathrm{D}$ & $\mathrm{D}$ & $\mathrm{D}$ \\
Spinner 1 & $\mathbf{3}$ & $\mathrm{D}$ & $\mathrm{D}$ & $\mathrm{D}$ & $\mathrm{D}$ & $\mathrm{D}$ \\
& $\mathbf{4}$ & $\mathrm{D}$ & $\mathrm{D}$ & $\mathrm{D}$ & $\mathrm{S}$ & $\mathrm{D}$ \\
& $\mathbf{5}$ & $\mathrm{D}$ & $\mathrm{D}$ & $\mathrm{D}$ & $\mathrm{D}$ & $\mathrm{S}$ \\
\hline
\end{tabular}

Note: D: Different, S: Same.

(b)

Figure 4.

Some examples of students' answers. 


\section{General Discussion, Conclusion and Proposals}

In this research, we determined the effect of teaching mathematics performed with the help of CSCM on 7th graders' conceptual learning of probability. From the findings, it may be suggested that the posttest scores of both groups show a significant increase when compared to the pretest results. Thus, both instructional methods can be argued to improve the students. Yet, when the improvements in the groups are compared it can be said that the intervention in the experimental group was more effective in terms of conceptual learning. When monitoring the students in the experimental group, it was observed that they enjoyed the process, were interactive, and had the opportunity to construct knowledge visually. These effects of CSCM on learning corresponded with the results of a great deal of studies (Anderson-Inman \& Zeitz, 1993; AndersonInman et al., 1998; Simone et al., 2001; Chang et al., 2002; Stoyanova \& Kommers, 2002; Brown, 2003; Baki \& MandaciŞahin, 2004; Kwon \& Cifuentes, 2009; Huang et al., 2012).

Contributions of groups' members to each other indicated that one of the other factors ensuring this process to be effective is cooperative learning strategy, because almost all positive effects of cooperative learning were effectively used during this process. During the instructions, it was seen that especially students whose learning motivations were low benefitted more from the process, through their partners. This result was in accordance with previous studies (Stoyanova \& Kommers, 2002; Brown, 2003; Kwon \& Cifuentes, 2009) that discussed the positive effects of working with the CSCM in cooperative groups. Moreover, feedbacks given in the system depending on students' answers enhanced the effectiveness of CSCM. In their study, Chang et al. (2001) referred to similar effect of feedbacks in CSCM environment.

Furthermore, it could be claimed the fact that different teachers conducted the instructions in each group was also effective in groups' different level of learning probability subject. That teachers decided on which approach to employ during the process and that they used it effectively influenced students' learning. Effective guidance by teacher (researcher) in experimental group, opportunities to talk and correct feedback given by researcher as much as possible, having students use CSCM effectively in cooperative groups and using dice, spinners and darts made the process effective. That the researcher followed the process in order to teach effectively could be explained by his/her professional competence. From this point of view, it can be stated that educatories' professional competence is one of the other important factors affecting this process. In this sense, many previous academic studies (Shulman, 1986, 1987; Ball, 1988, 1990; Hill, Rowan, \& Ball, 2005; Davis \& Simmt, 2006; Tchoshanov, 2011) highlighted the importance of this competence in order for performing effective instructions.

Regarding suggestions for further research, it is advisable to look into what should be done for the students' adaptation to work in CSCM. The effect of the CSCM on determining and remedying misconceptions should be investigated. These types of CSCM can be used as assessment tools besides teaching materials. By observing probability teaching process of different teachers (both through video-camera and participative observation), approaches employed by them and their effects on learning could be compared.

\section{REFERENCES}

Anderson-Inman, L., \& Zeitz, L. (1993). Computer-based concept mapping: Active studying for active learners. Computing Teacher, 21, 6-11.

Anderson-Inman, L., \& Horney, M. (1996). Computer-based concept mapping: Enhancing literacy with tools for visual thinking. Journal of Adolescent and Adult Literacy, 40, 302-306.

Anderson-Inman, L., Ditson, L. A., \& Ditson, M. T. (1998). Computerbased concept mapping: Promoting meaningful learning in science for students with disabilities. Information Technology and Disabilities, 5, 1-13.

Anderson-Inman, L., \& Ditson, L. (1999). Computer-based concept mapping: A tool for negotiating meaning. Learning and Leading with Technology, 26, 6-13.

Ayres, P., Sawyer. W., \& Dinham, S. (2004). Effective teaching in the context of a grade 12 high-stakes external examination in new south wales, Australia. British Educational Research Journal, 30, 141-165. doi: $10.1080 / 01411920310001630008$

Baker, M., \& Chick, H. L. (2007). Making the most of chance. Australian Primary Mathematics Classroom, 12, 8-13.

Baki, A., \& Mandaci-Şahin, S. (2004). Assessment of preservice teachers' mathematical learning through computer aided concept mapping method. TOJET, 3, 91-104.

Ball, D. L. (1988). Knowledge and reasoning in mathematical pedagogy: Examining what prospective teachers bring to teacher education. Unpublished Ph.D. Thesis, East Lansing, MI: Michigan State University.

Ball, D. L. (1990). The mathematical understandings that prospective teachers bring to teacher education. Elementary School Journal, 90, 449-466. doi:10.1086/461626

Batanero, C., \& Serrano, L. (1999). The meaning of randomness for secondary school students. Journal for Research in Mathematics Education, 30, 558-567. doi:10.2307/749774

Bezzina, F. (2004). Pupils' understanding of probabilistic \& statistics (14-15+) difficulties and insights for instruction. Journal of Maltese Education Research, 2, 53-67.

Black, P., \& Wiliam, D. (1998). Assessment and classroom learning. Assessment in Education, 5, 7-74. doi:10.1080/0969595980050102

Boaler, J. (1997). Experiencing school mathematics: Teaching styles, sex and setting. Buckingham: Open University Press.

Brown, D. S. (2003). High school biology: A group approach to concept mapping. The American Biology Teacher, 65, 192-197.

Chang, K. E., Sung, Y. T., \& Chen, S. F. (2001). Learning through computer-based concept mapping with scaffolding aid. Journal of Computer Assisted Learning, 17, 21-33.

Chang, K. E., Sung, Y. T., \& Chen, I. D. (2002). The effect of concept mapping to enhance text comprehension and summarization. The Journal of Experiment Education, 71, 5-23. doi:10.1080/00220970209602054

Chernoff, E. J. (2009). Sample space partitions: An investigative lens. Journal of Mathematical Behavior, 28, 19-29. doi:10.1016/j.jmathb.2009.03.002

Chiu, C. H., \& Hsiao, H. F. (2010). Group differences in computer supported collaborative learning: Evidence from patterns of Taiwanese students' online communication. Computers \& Education, 54, 427435. doi:10.1016/j.compedu.2009.08.026

Cohen, J. (1988). Statistical power analysis for the behavioral sciences. Hillsdale, NJ: Erlbaum.

Davis, B., \& Simmt, E. (2006). Mathematics-for-teaching: An ongoing investigation of the mathematics that teachers (need to) know. Educational Studies in Mathematics, 61, 293-319. doi:10.1007/s10649-006-2372-4

Erdem, E. (2011). An investigation of the seventh grade students' mathematical and probabilistic reasoning skills. Unpublished M.A. Thesis, Adıyaman: Adıyaman University.

Even, R., \& Kvatinsky, T. (2010). What mathematics do teachers with contrasting teaching approaches address in probability lessons? Educational Studies in Mathematics, 74, 207-222. doi:10.1007/s10649-010-9234-9

Fast, G. (1997). Using analogies to overcome student teachers' probability misconceptions. Journal of Mathematical Behavior, 16, 325344. doi:10.1016/S0732-3123(97)90011-0

Firat, S. (2011). The effect of mathematics teaching performed through 
educational computer games on conceptual learning. Unpublished M.A. Thesis, Adıyaman: Adiyaman University.

Fischbein, E., Nello, M. S., \& Marino, M. S. (1991). Factors affecting probabilistic judgements in children and adolescents. Educational Studies in Mathematics, 22, 523-549. doi:10.1007/BF00312714

Gürbüz, R. (2006a). Concept maps for the teaching of probability. 100th Year University Education Faculty Journal-Online, 3, 133151.

Gürbüz, R. (2006b). Development of practice sheets for probability concept. Cukurova University Education Faculty Journal, 31, 111123.

Gürbüz, R. (2007). The effects of computer aided instruction on students' conceptual development: A case of probability subject. Eurasion Journal of Educational Research, 28, 75-87.

Gürbüz, R. (2010). The effect of activity based instruction on conceptual development of seventh grade students in probability. International Journal of Mathematical Education in Science and Technology, 41, 743-767. doi:10.1080/00207391003675158

Gürbüz, R., Çatlıoğlu, H., Birgin, O., \& Erdem, E. (2010). An investigation of fifth grade students' conceptual development of probability concepts based on activity based instruction: A quasi-experimental study. Educational Sciences: Theory \& Practice, 10, 10531068 .

Gürbüz, R., \& Birgin, O. (2012). The effect of computer-assisted teaching on remedying misconceptions: The case of the subject "probability". Computers \& Education, 58, 931-941. doi:10.1016/j.compedu.2011.11.005

Gürbüz, R., Birgin, O., \& Çatlığlu, H. (2012). Comparing the probability-related misconceptions of pupils at different education levels. Croatian Journal of Education, 14, 307-357

Heinze-Fry, J. A., \& Novak, J. D. (1990). Concept mapping brings longterm movement towards meaningful learning. Science Education, 74, 461-472. doi: $10.1002 / \mathrm{sce} .3730740406$

Hill, H. C., Rowan, B., \& Ball, D. L. (2005). Effects of teachers' mathematical knowledge for teaching on student achievement. American Educational Research Journal, 42, 371-406. doi:10.3102/00028312042002371

Huang, H. S., Chiou, C. C., Chiang, H. K., Lai, S. H., Huang, C. Y., \& Chou, Y. Y. (2012). Effects of multidimensional concept maps on fourth graders' learning in web-based computer course. Computers \& Education, 58, 863-873. doi:10.1016/j.compedu.2011.10.016

Johnson, D. W., \& Johnson, R. T. (1989). Cooperation and competition (2nd ed.). Edina, MI: Interaction.

Jonassen, D. H. (1996). Computer in the classroom: Mindtools for critical thinking. Eaglewoods, NJ: Merill/Prentice Hall.

Jones, G. A., Langrall, C. W., Thornton, C. A., \& Mogill, T. A. (1997). A framework for assessing and nurturing young children's thinking in probability. Educational Studies in Mathematics, 32, 101-125.

Kahneman, D., \& Tversky, A. (1972). Subjective probability: A judgment of representativeness. Cognitive Psychology, 3, 430-454. doi:10.1016/0010-0285(72)90016-3

Kahneman, D. (2003). A perspective on judgment and choice: Mapping bounded rationality. American Psychologist, 58, 697-720. doi:10.1037/0003-066X.58.9.697

Keren, G. (1984). On the importance of identifying the correct "problem space". Cognition, 16, 121-128. doi:10.1016/0010-0277(84)90002-7

Kwon, S. Y., \& Cifuentes, L. (2009). The comparative effect of individually-constructed vs. collaboratively-constructed computer-based concept maps. Computers \& Education, 52, 365-375. doi:10.1016/j.compedu.2008.09.012

Lecoutre, M. P. (1992). Cognitive models and problem spaces in "purely random" situations. Educational Studies in Mathematics, 23, 557-568. doi:10.1007/BF00540060

Ledesma, E. F. R. (2010). Using an interactive computer system to support the task of building the notions of ratio and proportion. Creative Education, 1, 115-120. doi:10.4236/ce.2010.12017

Matin, M. A. (2012). Interactive computer-centered instructions for science and engineering education. Creative Education, 3, 375-379. doi:10.4236/ce.2012.33059

Nilsson, P. (2007). Different ways in which students handle chance encounters in the explorative setting of a dice game. Educational Studies in Mathematics, 66, 293-315. doi:10.1007/s10649-006-9062-0

Nilsson. P. (2009). Conceptual variation and coordination in probability reasoning. Journal of Mathematical Behavior, 28, 247-261. doi:10.1016/j.jmathb.2009.10.003

Novak, J. D., \& Gowin, B. (1984). Learning how to learn. New York: Cambridge University Press. doi:10.1017/CBO9781139173469

Novak, J. D., \& Cañas, A. J. (2006). The origins of the concept mapping tool and the continuing evolution of the tool. Information Visualisation Journal, 5, 175-184. doi:10.1057/palgrave.ivs.9500126

Polaki, M. V. (2002). Using instruction to identify key features of basotho elementary students' growth in probabilistic thinking. Mathematical Thinking and Learning, 4, 285-313. doi:10.1207/S15327833MTL0404 01

Pratt, D. (2000). Making sense of the total of two dice. Journal for Research in Mathematics Education, 31, 602-625. doi: $10.2307 / 749889$

Rautama, E. (2000). Extending the delivery of concept maps. AAPS project, ITiCSE. The 5th Annual Conference on Innovation and Technolology in Computer Science Education.

Royer, R., \& Royer, J. (2004). Comparing hand drawn and computer generated concept mapping. Journal of Computers in Mathematics and Science Teaching, 23, 67-81.

Shulman, L. S. (1986). Those who understand: Knowledge growth in teaching. Educational Researcher, 15, 4-14.

Shulman, L. S. (1987). Knowledge and teaching: Foundation of the new reform. Harvard Educational Review, 57, 1-22.

Simone, C. D., Schmid, R. F., \& McEwen, L. A. (2001). Supporting the learning process with collaborative concept mapping using computer-based communication tools and process. Educational Research and Evaluation, 7, 263-283 doi:10.1076/edre.7.2.263.3870

Slavin, R. E. (1987). Cooperative learning and cooperative school. Educational Leadership, 45, 7-13.

Slavin, R. (1996). Research on cooperative learning and achievement: What we know, what we need to know. Contemporary Educational Psychology, 21, 43-69. doi:10.1006/ceps.1996.0004

Stoyanova, N., \& Kommers, P. (2002). Concept mapping as a medium of shared cognition in computer-supported collaborative problem solving. Journal of Interactive Learning Research, 13, 111-133.

Sturm, J. M., \& Rankin-Erickson, J. L. (2002). Effects of hand-drawn and computer-generated concept mapping on the expository writing of middle students with learning disabilities. Learning Disabilities Research \& Practice, 17, 124-139. doi:10.1111/1540-5826.00039

Tchoshanov, M. A. (2011). Relationship between teacher knowledge of concepts and connections, teaching practice, and student achievement in middle grades mathematics. Educational Studies in Mathematics, 76, 141-164. doi:10.1007/s10649-010-9269-y

Tsai, C. C., Lin, S. S. J., \& Yuan, S. M. (2001). Students' use of webbased concept map testing and strategies for learning. Journal of Computer Assisted Learning, 17, 72-84. doi:10.1111/j.1365-2729.2001.00160.x

Willerman, M., \& Harg, R. A. (1991). The concept map as an advance organizer. Journal of Research in Science Teaching, 28, 705-711.

Yavuz, A. (2005). Effectiveness of conceptual change instruction accompanied with demonstrations and computer assisted concept mapping on students' understanding of matter concepts. Ph.D. Thesis, Ankara: Middle East Technical University. doi:10.1002/tea.3660280807 


\section{Appendix: Some Question Items in CLT}

$\mathbf{Q}_{1}$

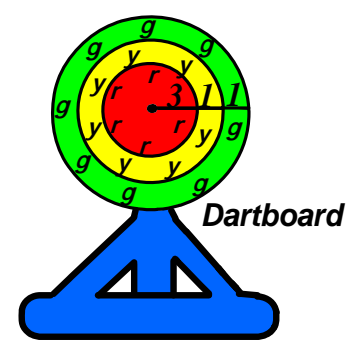

In the dartboard, whose radii lengths are shown above, " $r$ " represents red, " $g$ " represents green and " $y$ " represents yellow. As each shot targets at any yellow, green or blue color, the probability of targeting at which color is the lowest when a random shot occurs? Why? Could you use numerical expressions to support your ideas?

$\mathbf{Q}_{2}$

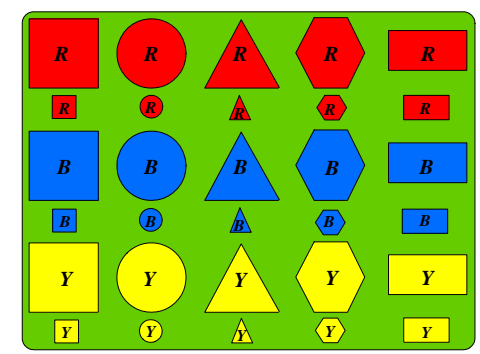

In the board shown above, " $R$ " represents red, " $B$ " represents blue and " $Y$ " represents yellow. What is theprobability of a randomlychosengeometricshapeto be blueorrectangle? Could you express your ideas numerically?

$\mathbf{Q}_{3}$

Family Gül areexpectingtheirsixthbaby. Their first five children are males. Having a male or female baby is more probable in this case? Why?

\section{$\mathbf{Q}_{4}$}

Ali and Veli will play a game by using toy cars on a 10 step long road. Each player will roll the two dice designed such as (222 333) and (444 666) at the same time. If the sum of the outcomes is even, Ali will move his toy car one step further. If the sum of the outcomes is odd, then Veli will do the same. The one who completes the 10-step long road earlier will win. In your opinion, who wins the game? Why?

$\mathbf{Q}_{5}$

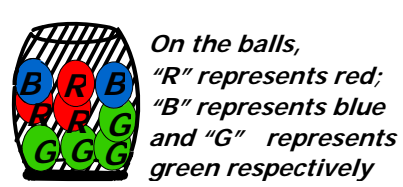

There are 4 green, 3 red and 2 blue balls, in total 9 balls in this basket. When you close your eyes, mix the balls and choose a ball in the basket, the probability of getting which colored ball is the highest? Why? Could you use numerical expressions to support your ideas?

$\mathbf{Q}_{6}$

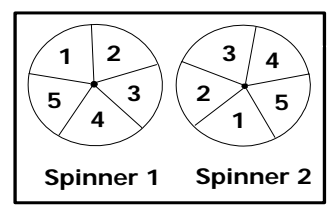

Do you think the probability of getting the same numbers or different numbers is higher when spinners above are turned together? Why? Could you express your ideas numerically? 